REVISTA X, Curitiba, volume 13,n.1,p.57-86, 2018.

Dossiê Especial: Português como Língua Adicional em contextos de minorias:

(co)construindo sentidos a partir das margens

BIZON \& DINIZ (Orgs.)

\title{
PORTAS ENTREABERTAS DO BRASIL: NARRATIVAS DE MIGRANTES DE CRISE SOBRE POLÍTICAS PÚBLICAS DE ACOLHIMENTO
}

\author{
Brazil's Slightly Open Doors: Crisis Migrants' Narratives about Welcoming Public \\ Policies
}

Helena Regina Esteves de CAMARGO, IEL-UNICAMP ${ }^{1}$

RESUMO: Em um momento em que o Brasil ingressa na rota de novos fluxos migratórios em decorrência das consequências da globalização que, para muitos, apresenta-se em sua versão perversa (SANTOS, 2001), faz-se necessário investigar como os migrantes vivenciam as políticas públicas voltadas para seu acolhimento e inserção social no país. O presente artigo objetiva, a partir das narrativas de dois migrantes residentes no município de São Paulo, analisar como mecanismos de regulamentação de entrada e permanência no país e políticas de acolhimento disponíveis são vivenciados por eles e, partindo dessas reflexões, levantar algumas implicações sobre políticas de acolhimento. As narrativas foram geradas por meio de conversas informais áudio-gravadas com o objetivo de relatar a experiência vivida pelos migrantes em relação à acolhida e às possibilidades de inserção social no país. As análises das narrativas mostram que, apesar dos avanços legislativos e de ações institucionais voltadas ao acolhimento e inserção social, ainda fazem falta medidas que viabilizem a concessão de vistos de entrada, a permissão ao vínculo empregatício, bem como políticas de línguas para ampliar o acesso à informação e auxiliar no processo de (re)reterritorialização (HAESBAERT, 2004; BIZON, 2013).

Palavras-chave: Migrações; Políticas Públicas; Acolhimento; Narrativas.

ABSTRACT: At a time in which Brazil enters the route of new migration flows due to the consequences of globalization, which, to many people, presents itself in its perverse version (SANTOS, 2001), it is necessary to investigate how migrants experience the public policies meant to welcome and include them in society. The objective of this paper is, from two crisis migrants' narratives who reside in the city of São Paulo, to analyze how the mechanisms that regulate entrance and stay in the country and the available welcoming policies are experienced by them. From these reflections, this paper aims to raise a few implications on welcoming policies. The narratives have been generated through informal audio recorded conversations with the objective to report the experience lived by the migrants when it comes to their welcoming and to their social inclusion in the country. The narrative analyses show that, in spite of the legislative advances and the institutional actions towards welcoming and social inclusion, there is still a lack of measures that enable the granting of entrance visas, job

\footnotetext{
${ }^{1}$ Doutoranda em Linguística Aplicada. Email: helcamargo@yahoo.com.br
} 
REVISTA X, Curitiba, volume 13,n.1,p. 57-86, 2018.

Dossiê Especial: Português como Língua Adicional em contextos de minorias:

(co)construindo sentidos a partir das margens

BIZON \& DINIZ (Orgs.)

permits, and language policies to broaden information access and to aid the (re)territorialization process (HAESBAERT, 2004; BIZON, 2003).

Key-words: Migrations; Public Policies; Welcoming; Narratives

\section{INTRODUÇÃO}

A imigração não é um fator novo na constituição da população brasileira. No entanto, os números, os países de origem e as motivações das pessoas que se deslocam para o Brasil hoje são diferentes daqueles que caracterizaram nossa imigração histórica. No contexto recente das imigrações no Brasil, a compreensão dos fluxos migratórios requer que consideremos a face perversa da globalização (SANTOS, 2001) ${ }^{2}$ como fator estrutural da mobilidade humana, bem como as condições de recebimento de migrantes oferecidas pelo país.

Entendida como "o ápice do processo de internacionalização do mundo" (ibidem, p. 23), a globalização cultiva, devido à predominância da informação como sistema técnico dos tempos atuais, um mercado global em que as empresas extrapolam as fronteiras nacionais e o capital circula livremente pelo mundo, aproximando os interesses do Estado aos do Mercado. A técnica da informação alcança a totalidade de cada país, direta ou indiretamente, permitindo que cada lugar tenha acesso ao lugar do outro e que ações ocorram simultaneamente em diferentes partes do mundo. A expansão do espaço e a convergência dos momentos permitem que a produção seja fragmentada em diferentes localidades do mundo para ser, posteriormente, unida e articulada pela "inteligência" da corporação, promovendo uma nova divisão internacional do trabalho regida pelas grandes empresas transnacionais. Nota-se, portanto, uma mudança na

\footnotetext{
${ }^{2}$ De acordo com Milton Santos (2001), para a maioria das pessoas, a globalização se impõe de maneira perversa, pois gera desemprego, traz de volta doenças extirpadas, aumenta a pobreza, generaliza a fome e o desabrigo, mantém a mortalidade infantil, promove males espirituais e morais, como os egoísmos, cinismos e a corrupção, e diminui o acesso à educação de qualidade. $\mathrm{O}$ autor relaciona a perversidade sistêmica à adesão desenfreada aos comportamentos competitivos que atualmente caracterizam as ações hegemônicas.
} 
REVISTA X, Curitiba, volume 13,n.1,p. 57-86, 2018.

Dossiê Especial: Português como Língua Adicional em contextos de minorias:

(co)construindo sentidos a partir das margens

BIZON \& DINIZ (Orgs.)

função do Estado frente à economia de mercado (GONÇALVES, 2005), que pode ser descrita nas seguintes palavras de Milton Santos (2001, p. 66):

Não é que o Estado se ausente ou se torne menor. Ele apenas se omite quanto ao interesse das populações e se torna forte, mais ágil, mais presente, ao serviço da economia dominante.

Enquanto se amplia o papel político das empresas na regulação da vida social, encolhem-se as funções sociais e políticas do Estado, ocasionando o aumento do desemprego, generalização da fome e do desabrigo, a proliferação de novas e velhas enfermidades, a permanência da mortalidade infantil - a despeito dos avanços da medicina e das tecnologias da informação - e a falta de acesso à educação de qualidade. Além disso, Sassen (2014, p. 12) nos lembra que "crescimento econômico nunca foi benigno", sendo causa de devastação ambiental e, até mesmo, de conflitos civis (quando pensamos que a exploração de recursos naturais é foco de interesses políticos), resultando no que a autora denomina "expulsão" de inúmeras pessoas. Todos esses fatores fomentam a migração no mundo, uma vez que impactam os sistemas de produção locais, abalam o meio ambiente e desestabilizam relações políticas, resultando na falta de condições dignas de se viver em muitos países.

Embora haja duas classificações jurídicas principais para qualificar os migrantes nas leis brasileiras - refugiados e imigrantes -, é possível considerar as migrações que são forçadas por problemas econômicos, políticos, civis, religiosos e humanitários como “migrações de crise" (CLOCHARD, 2007), conceito estendido e aprofundado por Baeninger e Peres (2017, p. 122). Nessa ampliação, as autoras incorporam os diversos tipos de migrantes, tais como imigrantes com a condição jurídica de refugiado, solicitantes de refúgio, com visto humanitário e refugiados ambientais, no escopo teórico-conceitual da migração de crise. Além de indicar a presença da crise nos países de origem desses deslocados, as autoras apontam como essa crise também diz respeito ao país de destino, frequentemente despreparado para receber os fluxos migratórios, evidenciando, assim, “o caráter bilateral da crise” (BIZON \& CAMARGO, 2018, p. 712). 
REVISTA X, Curitiba, volume 13,n.1,p. 57-86, 2018.

Dossiê Especial: Português como Língua Adicional em contextos de minorias:

(co)construindo sentidos a partir das margens

BIZON \& DINIZ (Orgs.)

Levando-se em conta a ampliação do conceito de migração de crise e o fato de que o emigrante é, ao mesmo tempo, imigrante, uma vez que não é possível ter ingressado em um lugar sem ter saído de outro (SAYAD, 2000), retiramos os prefixos que especificam as direções do movimento e referimo-nos às pessoas que se deslocam para o Brasil vindas de outros países devido a causas críticas por migrantes de crise. Acreditamos que o termo migrante traduza melhor o dinamismo dos processos migratórios atuais, indicando que o Brasil é também rota, e não somente destino, e que, por estarem envolvidos simultaneamente nas sociedades de origem e de destino, muitos migrantes são transnacionais (GLICK-SCHILLER, 1999; BAENINGER \& PERES, 2017).

A partir da conceituação ampliada de migração de crise proposta por Baeninger e Peres (2017), entendemos que a crise vivenciada pela sociedade receptora diante da chegada dos fluxos migratórios esteja vinculada aos instrumentos jurídicos disponíveis e às políticas de acolhimento constituídas a partir desses instrumentos, que podem estar organizadas tanto nas verticalidades - que são o espaço hegemônico, as políticas oficiais/institucionalizadas - quanto nas horizontalidades - que representam o espaço banal, as políticas informais produzidas pela sociedade civil (SANTOS, 2001). Nas verticalidades, um espaço de fluxos é formado por um conjunto de pontos adequados às tarefas produtivas hegemônicas características das atividades econômicas que comandam nosso período histórico, tais como a industrialização, o fluxo de capitais e mercadorias e as leis, por exemplo. Tais tarefas produtivas exigem velocidade e fluidez para atenderem aos interesses dos "macroatores", ou seja, "aqueles que de fora da área determinam as modalidades internas" (SANTOS, 2001, p. 106) e que podem participar e se beneficiar do processo de produção. Nas horizontalidades, em vez de redes, formam-se extensões contínuas criadoras de um "espaço banal” (ibidem, p. 108) onde os processos de produção ocorrem e onde se atendem aos interesses de todos os atores (empresas, instituições, pessoas, vivências) considerados em sua contiguidade. Nas horizontalidades, todos os agentes são implicados de alguma forma, e todos os tempos, em suas diferentes velocidades, são imbricados propiciando condições para que as produções sejam interdependentes e localizadas dentro de um espaço geográfico local 
REVISTA X, Curitiba, volume 13,n.1,p. 57-86, 2018.

Dossiê Especial: Português como Língua Adicional em contextos de minorias:

(co)construindo sentidos a partir das margens

BIZON \& DINIZ (Orgs.)

que também é um fator de produção, já que as atividades exercidas nele são criadas e alimentadas por ele mesmo. Milton Santos nota que, apesar de a globalização ser um processo marcadamente hegemônico, ela é um processo complexo e multifacetado que tem implicações tanto no eixo vertical quanto horizontal. À medida que políticas verticais são organizadas e as mobilidades transnacionais intensificam-se nas diferentes instituições, por permitirem ações e temporalidades mais variadas, as horizontalidades podem propiciar novas formas de resistência e fazer com que novas vozes sejam ouvidas. É o que se nota com as ações da sociedade civil que conduziram à criação da Lei Municipal de Migração de São Paulo (Lei 16.478/16) e da Nova Lei de Migração federal (Lei 13.445/17).

Os avanços percebidos nas políticas públicas voltadas para a população migrante têm grande relevância para sua (re)territorialização (HAESBAERT, 2004; BIZON, 2013), aqui entendida como o processo de apropriação material, simbólica e cultural do território ocupado. Sendo o território uma construção social, histórica e política, e não somente um espaço físico, ele é permeado por relações de poder. Portanto, para entendermos os processos de (re)territorialização, é fundamental atentarmo-nos para quem delimita ou controla o espaço de quem, e as consequências desse processo, pois, conforme explica Haesbaert (2004, p. 262),

deter o controle seria territorializar-se. Quando somos nós que definimos o território dos outros, de forma imposta, eles não estão de fato se territorializando, pois ser "territorializado" por outros, especialmente quando completamente contra nossa vontade e sem opção, significa desterritorializarse. Assim, "reterritorialização" implica um movimento de resistência - à desterritorialização imposta pelo movimento de territorialização comandado por outros.

Note-se, portanto, que o processo de desterritorialização está sempre associado ao de reterritorialização e que ambos processos se referem "a uma noção de território ao mesmo tempo como dominação político-econômica (sentido funcional) e apropriação ou identificação cultural (sentido simbólico)” (ibidem, p. 312). Daí a possibilidade de estarmos territorializados no sentido funcional ao mesmo tempo em que nos encontramos desterritorializados no sentido simbólico, ou vice-versa. A desterritorialização, na visão do autor, é um processo relacionado a ocorrências de 
REVISTA X, Curitiba, volume 13,n.1,p. 57-86, 2018.

Dossiê Especial: Português como Língua Adicional em contextos de minorias:

(co)construindo sentidos a partir das margens

BIZON \& DINIZ (Orgs.)

efetiva instabilidade ou fragilização territorial sofridas pelos grupos sociais mais excluídos ou segregados que, como tais, se encontram impossibilitados de construir e exercer controle sobre seus territórios tanto no sentido funcional quanto simbólico. Portanto, entendida a partir de sua perspectiva político-econômica e simbólico cultural, a desterritorialização pode ser vista como exclusão social.

Considerando a legislação e as políticas públicas - horizontais e verticais voltadas para a população migrante, os objetivos deste artigo são: (i) analisar, com base nas narrativas de dois migrantes de crise residentes no município de São Paulo, como os mecanismos de regulamentação de entrada e permanência no país e as políticas de acolhimento disponíveis são vivenciados por esses atores; (ii) a partir dessas reflexões, levantar algumas implicações sobre políticas de acolhimento. Para tanto, o presente trabalho divide-se em quatro seções, além desta introdução: a primeira traça um panorama das políticas de migração e acolhimento no país; a segunda discorre sobre a metodologia que embasa a realização da pesquisa e a geração dos registros; a terceira, subdividida em duas partes, apresenta a análise dos dados, e, por fim, a quarta seção traz algumas considerações acerca das discussões realizadas.

\section{O PANORAMA DAS POLÍTICAS DE MIGRAÇÃO E DE ACOLHIMENTO NO BRASIL}

As crises provocadas pelo capitalismo global tendem a abalar as noções de soberania econômica e política dos Estados-nação. As incertezas que surgem desse abalo criam uma ansiedade sentida pelos indivíduos em relação aos direitos sociais proporcionados pelo Estado (acesso a trabalho, previdência social, saúde, segurança etc.), uma vez que o acesso a esses direitos está ligado “a quem 'você' é e, portanto, a quem 'eles' são” (APPADURAI, 2006/2009, p. 16). As incertezas e ansiedades são intensificadas à medida que cresce o movimento de pessoas em larga escala, fazendo parecer que são os migrantes a causa, e não as vítimas, da referida crise. Nesse sentido, os migrantes são representados como uma ameaça à estabilidade política, econômica e social, que se percebe ainda mais abalada em tempos de crise no país. A reação de parte 
REVISTA X, Curitiba, volume 13,n.1,p. 57-86, 2018.

Dossiê Especial: Português como Língua Adicional em contextos de minorias:

(co)construindo sentidos a partir das margens

BIZON \& DINIZ (Orgs.)

dos nacionais contra a suposta ameaça é a tentativa de reconstruir o Estado a partir da reafirmação do "ethnos nacional" (ibidem, p. 14), ou seja, da crença de que sua população é homogênea e de caráter excepcional, corporificando no Outro o medo gerado pela ansiedade em um processo de "racialização" (BIZON \& CAVALCANTI, 2018). De acordo com as autoras, a racialização

\begin{abstract}
envolve construção discursiva do Outro como inferior/subalterno. A metáfora subjacente ao conceito poderia ser a da "biologização", anexando status e valores a características físicas/fenotípicas, que passam a definir o Outro. Conforme aponta Butler (2004, p. 259), na racialização, “a ênfase não é apenas social em um sentido restrito, mas em um imaginário socialmente articulado, a produção especular de expectativas raciais e o distanciamento visual e o funcionamento visceral do significante racial" (BIZON \& CAVALCANTI, 2018, p. 228).
\end{abstract}

A consequência dessa reação, como se pode notar, é o fechamento das fronteiras, principalmente dos países considerados desenvolvidos, que, somado à participação nos principais tratados de Direitos Humanos, às políticas externas ${ }^{3}$ e ao relativo crescimento da economia do país até 2014, colocam o Brasil na rota das migrações Sul-Sul (BAENINGER et al, 2018).

Entre os desafios trazidos pelo novo contexto, encontram-se a implementação da Lei $13.445 / 2017$, que substitui a Lei $6.815 / 1980$, há muito tempo criticada por ser retrógada e contrária à Constituição e aos tratados internacionais firmados pelo Brasil (VENTURA, 2010), e a elaboração de políticas de acolhimento que promovam e viabilizem a (re)territorialização dos migrantes de crise no Brasil por meio do acesso a informações, do trabalho legalizado e do direito ao aprendizado da língua portuguesa, para citar algumas ações.

A Lei 13.445/2017, que foi regulamentada e entrou em vigor em novembro de 2017, representa um avanço na luta por direitos igualitários entre nacionais e migrantes, pois, baseada nos Direitos Humanos, encoraja a regularização migratória. Por outro lado, os vetos feitos pelo presidente Michel Temer levantam algumas preocupações quanto à maneira como a lei será interpretada, a começar pelo veto do inciso I do parágrafo $1^{\circ}$ do artigo $1^{\circ}$, que trata do conceito de migrante. Tendo como referência o

\footnotetext{
${ }^{3}$ Baeninger \& Peres (2017) apontam a presença militar brasileira no Haiti no início do século XXI como um fator que coloca o Brasil como rota e destino da migração haitiana.
} 
REVISTA X, Curitiba, volume 13,n.1,p. 57-86, 2018.

Dossiê Especial: Português como Língua Adicional em contextos de minorias:

(co)construindo sentidos a partir das margens

BIZON \& DINIZ (Orgs.)

caráter extremamente dinâmico dos fluxos migratórios atuais e entendendo que os Direitos Humanos são inalienáveis a qualquer pessoa, o referido inciso conceituava por migrante "a pessoa que se desloca de país ou região geográfica ao território de outro país ou região geográfica, incluindo o imigrante, o emigrante, o residente e o apátrida" (BRASIL, 2017b). O veto foi justificado sob o argumento de que

o dispositivo estabelece conceito demasiadamente amplo de migrante, abrangendo inclusive o estrangeiro com residência em país fronteiriço, o que estende a todo e qualquer estrangeiro, qualquer que seja sua condição migratória, a igualdade com os nacionais, violando a Constituição em seu artigo 5o, que estabelece que aquela igualdade é limitada e tem como critério para sua efetividade a residência do estrangeiro no território nacional ${ }^{4}$.

A lei, portanto, limita o status de imigrante à pessoa de outro país ou apátrida que se estabelece temporária ou permanentemente no Brasil por meio de residência no país, o que coloca o assentamento no território nacional como condição sine qua non para a obtenção de igual acesso a direitos sociais que os nacionais, evidenciando a manutenção das ideologias que permearam a política imigratória de meados do século XIX ao início do século XX e construíram a imagem do imigrante desejável como aquele que vem povoar o território e, muito provavelmente, somar à força de trabalho do país (SEYFERTH, 2008). Além disso, classificar quem pode se igualar aos nacionais no acesso aos bens providos pelo Estado remete ao ethnos nacional e às incertezas provocadas pela perda do controle político e econômico do Estado-nação, que são a base da xenofobia e de processos de racialização.

Dentre os avanços trazidos pela Lei 13.445/2017, destacamos o artigo 14, que possibilita a concessão do visto temporário ao migrante com o intuito de estabelecer residência temporária no país por motivo de acolhida humanitária. Conforme esclarecido no parágrafo $3^{\circ}$ desse artigo,

o visto temporário para acolhida humanitária poderá ser concedido ao apátrida ou ao nacional de qualquer país em situação de grave ou iminente instabilidade institucional, de conflito armado, de calamidade de grande proporção, de desastre ambiental ou de grave violação de direitos humanos

4 Disponível em <http://www.planalto.gov.br/ccivil_03/_Ato2015-2018/2017/Msg/VEP-163.htm>. Acesso em: 22/09/2017. 
REVISTA X, Curitiba, volume 13,n.1,p. 57-86, 2018.

Dossiê Especial: Português como Língua Adicional em contextos de minorias:

(co)construindo sentidos a partir das margens

BIZON \& DINIZ (Orgs.)

ou de direito internacional humanitário, ou em outras hipóteses, na forma de regulamento" (BRASIL, 2017).

Incluir a acolhida humanitária no rol dos motivos para a concessão de vistos temporários pode ser visto como uma reação favorável às demandas lançadas pelas migrações de crise. Além disso, é uma medida que deverá diminuir as solicitações de refúgio, acelerando o processo de análise para seu resultado final, pois alguns "projetos migratórios" (PEREIRA, 2012), ou seja, os arranjos familiares, o acionamento e as formas de acesso às redes de migrantes e as formas de ingresso e permanência no destino, implicam solicitar a condição de refúgio, a despeito da situação do migrante classificá-lo sob a definição de refugiado ou não. Isso porque o Brasil tem uma das leis de refúgio consideradas mais avançadas: a Lei $\mathrm{n}^{\circ}$ 9.474/1997 (BRASIL, 1997). Qualquer pessoa que chegue ao território brasileiro, ainda que sem documento e por ingresso irregular, ao solicitar refúgio, tem, segundo a lei, direito à permanência no território brasileiro, ao trabalho, à educação, à facilitação do reconhecimento de diplomas e certificados, dos requisitos para a obtenção da condição de residente e do ingresso em instituições acadêmicas de todos os níveis. Como o deferimento do pedido de refúgio não é requisito para a garantia desses direitos, que podem ser desfrutados pelo solicitante de refúgio enquanto ele aguarda a decisão do Comitê Nacional para os Refugiados (CONARE), muitos migrantes adotam a solicitação de refúgio como estratégia.

É o que se verificou quando o fluxo migratório haitiano começou a chegar ao Brasil pelas fronteiras terrestres em 2010 (BAENINGER; PERES, 2017) e, mais recentemente, com a migração venezuelana. A partir de então, o Conselho Nacional de Imigração (CNIg), órgão misto relacionado ao Ministério do Trabalho e Emprego, estabeleceu e renovou, até outubro de 2017, a Resolução Normativa $n^{\circ}$ 97/2012, que concede os vistos em caráter humanitário aos haitianos, e a Resolução Normativa $\mathrm{n}^{\circ}$ 126/2017, que permite concessão de residência temporária para migrantes que tenham ingressado por fronteira terrestre e sejam naturais dos países fronteiriços.

Em tempos que suscitam o fortalecimento das localidades, Oomen (2017) aponta que o status legal de cidadão, com direitos e responsabilidades relacionados a ele, tem 
REVISTA X, Curitiba, volume 13,n.1,p. 57-86, 2018.

Dossiê Especial: Português como Língua Adicional em contextos de minorias:

(co)construindo sentidos a partir das margens

BIZON \& DINIZ (Orgs.)

sido formalizado, cada vez mais, por outras autoridades políticas e não unicamente pelo Estado-nação. A partir da percepção de que existe uma "comunidade mundial" que garante direitos a todos os indivíduos por meio de um sistema expansivo dos tratados internacionais de Direitos Humanos e que, cada vez mais, as autoridades locais formalizam a garantia de direitos às pessoas que vivem dentro de suas fronteiras, criando uma espécie de "cidadania urbana" (OOMEN, 2017, p. 57), podemos entender que as políticas que definem e reconhecem os direitos dos migrantes estão articuladas em uma interação entre as escalas local, nacional, regional e internacional do Governo (idem). A cidadania moldada por essa interação é chamada por Oomen $(2017$, p. 60) de “cidadania glocal". Tal conceito faz ecoar o entendimento de que

\footnotetext{
a possibilidade de cidadania plena das pessoas depende de soluções a serem buscadas localmente, desde que, dentro da nação, seja instituída uma federação de lugares, uma nova estruturação político-territorial, com a indispensável redistribuição de recursos, prerrogativas e obrigações (SANTOS, 2001, p. 113).
}

Podemos observar um movimento de autoridades locais na direção da cidadania glocal quando, em novembro de 2014, a prefeitura de São Paulo inaugurou o Centro de Referência e Atendimento para Imigrantes (CRAI-SP), órgão encarregado de prover atendimento especializado e multilíngue ao público migrante a fim de orientar para a regulação migratória e prover outros serviços de assistência à população migrante. Posteriormente, em julho de 2016, a prefeitura de São Paulo aprovou a Lei Municipal 16.478, que regulamenta a Política Municipal para a População Migrante. Essa lei, que antecede a Lei de Migração federal, representa uma ação pioneira no Brasil na medida em que pretende garantir aos migrantes o acesso a direitos sociais independentemente de sua situação migratória documental.

Por essa lei, está previsto aos migrantes o direito à saúde, à assistência social, ao trabalho, à educação na rede de ensino público municipal, a programas habitacionais, ao combate à xenofobia e à divulgação de informações sobre os serviços públicos municipais direcionados a eles. Além do direito aos serviços sociais, a lei municipal também considera a necessidade de formar os agentes públicos atuantes para a sensibilização quanto à realidade da imigração em São Paulo, o que inclui orientação 
REVISTA X, Curitiba, volume 13,n.1,p. 57-86, 2018.

Dossiê Especial: Português como Língua Adicional em contextos de minorias:

(co)construindo sentidos a partir das margens

BIZON \& DINIZ (Orgs.)

sobre direitos humanos, direitos dos migrantes, legislação concernente, interculturalidade e aprendizagem de línguas. A lei ainda estipula a contratação de agentes públicos migrantes e prevê a criação, no âmbito da Secretaria Municipal de Direitos Humanos e Cidadania, do Conselho Municipal de Imigrantes, possibilitando aos migrantes certa representatividade na elaboração das políticas do munícipio. Essas diretrizes são primordiais para uma inserção social efetiva com vistas à (re)territorialização (HAESBAERT, 2004; BIZON, 2013) dos migrantes de crise, uma vez que refletem os três cursos de ação necessários para o fortalecimento político das minorias: (i) legislações favoráveis a elas, (ii) sua politização e (iii) da educação do seu entorno (MAHER, 2007).

O que se nota a partir da vigência dessa lei são ações que começam a encaminhar políticas públicas para o acolhimento dos migrantes de crise, como o projeto Portas Abertas: Português para Imigrantes ${ }^{5}$, que abriu 600 vagas em 10 escolas da rede municipal para alunos migrantes da rede, seus familiares e comunidades se matricularem mediante apresentação de qualquer documento. Iniciativas como essa são relevantes para o processo de (re)territorialização dos migrantes de crise, uma vez que “conhecer a língua oficial do país acolhedor não só é um fator fundamental no processo de inclusão e empoderamento social dos imigrantes, como também é um direito deles" (OLIVEIRA \& SILVA, 2017, p. 147). A relevância é ainda maior se considerarmos que, apesar do nosso processo histórico de imigração ter sido, frequentemente, pautado por uma perspectiva de assimilação dos migrantes (SEYFERTH, 2008) e algumas políticas linguísticas instituídas desde a colonização terem excluído e proibido outras línguas em favor do português (CAMPOS, 2006), o ensino da língua nacional para os migrantes de crise nunca foi pauta das políticas públicas e continua não sendo na lei federal.

A falta de legislações que instituam e regulamentem o ensino de português faz com que ele esteja predominantemente a cargo da sociedade civil, ficando sob

\footnotetext{
${ }^{5}$ Cf. BIZON \& CAMARGO, 2018, para uma descrição mais detalhada desta e de outras ações de acolhimento aos migrantes de crise no município de São Paulo.
} 
REVISTA X, Curitiba, volume 13,n.1,p. 57-86, 2018.

Dossiê Especial: Português como Língua Adicional em contextos de minorias:

(co)construindo sentidos a partir das margens

BIZON \& DINIZ (Orgs.)

responsabilidade de ONGs e pastorais ${ }^{6}$, que contam com professores voluntários para oferecer cursos de português para os migrantes de crise. Considerando que, em geral, os migrantes não são falantes de português como língua materna, as metodologias, nesse contexto, devem considerar as especificidades do ensino de língua adicional e possibilitar, por meio da aprendizagem de saberes linguístico-discursivos, um “movimento de apropriação material e simbólica do território, concebido não apenas em sua dimensão física/geográfica/material, mas também como ator e objeto das políticas, resultado constante de atos ou agenciamentos" (LOPEZ, 2016, p. 37). Nesse sentido, não basta simplesmente adaptar os saberes já produzidos na área de Português como Língua Adicional (PLA) para um novo contexto de ensino-aprendizagem (LOPEZ \& DINIZ, no prelo); é necessário considerar os fatores linguísticos e extra-linguísticos, como o fato de muitos migrantes de crise serem multilíngues, as condições psicossociais do refúgio, a necessidade urgente de aprendizagem para inserção no mercado de trabalho e a integração com a sociedade envolvente (AMADO, 2013). Por requerer considerações específicas e dirigir-se a um público específico, migrantes de crise, essa área de ensino de português é chamada por alguns pesquisadores (AMADO, 2013; LOPEZ, 2016; LOPEZ \& DINIZ, no prelo; SÃO BERNARDO, 2016; GROSSO, 2010) de Português como Língua de Acolhimento (PLAc). Lopez \&Diniz (no prelo, s/p) assim a definem:

A ramificação da subárea de Português como Língua Adicional (PLA) - integrante, portanto, da área de Linguística Aplicada - que se dedica à pesquisa e ao ensino de português para imigrantes, com destaque para deslocados forçados, que estejam em situação de vulnerabilidade e que não tenham o português como língua materna.

Considerando que o termo Português como Língua de Acolhimento tem sua origem no contexto de imigração e refúgio de Portugal, é válido apontar algumas ressalvas quanto à sua transposição para o contexto brasileiro. Como esclarece Anunciação (2018, neste dossiê), o ensino de PLAc faz parte de uma política de Estado

\footnotetext{
${ }^{6}$ A Secretaria Municipal de Direitos Humanos e Cidadania da Prefeitura de São Paulo, por meio da Coordenação de Políticas para Imigrantes (CPMig) e da Organização Internacional do Trabalho (OIT), fez um mapeamento das organizações não governamentais, associações e pastorais que oferecem cursos de português aos migrantes de crise. O mapeamento está disponível em Disponível em <http://www.prefeitura.sp.gov.br /cidade/ secre tarias/ upload/ direitos humanos/Mapeamento\%20cursos\%20de\%20portugues.pdf>. Acesso em 01/09/2017.
} 
REVISTA X, Curitiba, volume 13,n.1,p. 57-86, 2018.

\section{Dossiê Especial: Português como Língua Adicional em contextos de minorias:}

(co)construindo sentidos a partir das margens

BIZON \& DINIZ (Orgs.)

presente em todo território português: o programa Portugal Acolhe - Português para Todos. Em vigor desde 2007, o referido programa conta com material didático, currículo padronizado e divisão dos percursos de formação por "áreas de competência" (CABETE, 2010), compreendidas como língua portuguesa, cidadania e português técnico. A área de competência relativa à língua portuguesa é ainda subdividida em A e B, em correspondência ao Quadro Europeu Comum de Referência para Línguas. Ao concluírem os cursos, os migrantes e refugiados, para quem o programa se direciona, obtêm uma certificação de língua portuguesa, à qual está condicionada à permissão à nacionalidade, à residência permanente e/ou ao status de residente de longo prazo (nível A2) ${ }^{7}$. Portanto, concordamos com R. Anunciação (ibid., p. 41) que seja problemático transpor o conceito Português como Língua de Acolhimento ao contexto brasileiro de migração de crise, uma vez que

quando condiciona a inserção social do indivíduo no novo país de domicílio ao "domínio" da língua nacional, esse conceito apresenta uma visão reificada de língua, que tem sua origem na criação dos Estados nacionais, defendendo a ideia de que o pertencimento a uma comunidade constitui-se no "domínio" da língua nacional (MAKONI \& PENNYCOOK, 2005) [...]

Outro fator criticado pela autora é o condicionamento da conclusão dos cursos e obtenção de certificação em língua portuguesa ao acesso a direitos sociais. Nesse sentido, o programa Portugal Acolhe não parece representar uma política de acolhimento, mas sim de assimilacionismo, em que o ensino/aprendizado da língua portuguesa é utilizado como um mecanismo de seleção e, consequentemente, de exclusão daqueles que não incorporaram a língua e as construções culturais locais.

Embora o ensino/aprendizado do português seja fundamental por oportunizar o conhecimento e exercício dos direitos e deveres sociais dos migrantes de crise, ele não deve ser visto como a única ou melhor política de línguas possível. Oliveira \& Silva (2017, p. 148) nos lembram que esse tipo de raciocínio remete a "uma visão de sociedade linguisticamente homogênea e tem raízes históricas”, já que obrigar o uso de uma língua e proibir o uso de outras foram medidas adotadas para enfatizar a unidade

\footnotetext{
7 Disponível no site do Alto Comissariado para as Migrações do Governo português: <http://www.acm.gov.pt/-/programa-ppt-portugues-para-todos>. Acesso em: 23/10/2017.
} 
REVISTA X, Curitiba, volume 13,n.1,p. 57-86, 2018.

Dossiê Especial: Português como Língua Adicional em contextos de minorias:

(co)construindo sentidos a partir das margens

BIZON \& DINIZ (Orgs.)

nacional no processo de formação do Estado brasileiro (cf. CAMPOS, 2006), propagando o mito do monolinguismo no Brasil (CAVALCANTI, 1999; MAHER, 2013). Portanto, ao pensarmos políticas de línguas para a inserção social dos migrantes de crise, é preciso incluir suas línguas nos atendimentos públicos. É preciso considerar, nesse sentido, que aprender uma nova língua leva mais tempo do que o disponível para algumas situações imediatas na chegada ao país, como preencher o formulário para solicitação de refúgio ou obter os documentos necessários para ter acesso a direitos civis, políticos, econômicos, sociais e culturais. Na medida em que as barreiras linguísticas impedem o acesso aos direitos sociais, Oliveira e Silva (2017) indicam a falta de tradutores e intérpretes nos serviços públicos como uma violação dos direitos humanos. A falta de servidores falantes das línguas dos migrantes também poderia ser compreendida da mesma forma, sinalizando a iminente necessidade de "um plano de capacitação de membros e servidores de forma multidisciplinar, inclusive com o aprendizado instrumental mínimo de línguas estrangeiras" (C. ANUNCIAÇÃO, 2018, p. 633).

É indispensável reconhecermos a atuação da sociedade civil, por meio de ONGs e de instituições religiosas, na elaboração e execução de políticas de acolhimento, incluindo as relacionadas às línguas (OLIVEIRA \& SILVA, 2017; PARISE, 2016; AMADO, 2013). Embora essa atuação seja imprescindível, uma vez que se dá em um espaço que permite variadas formas de tempo e agência, provendo os mais diversos tipos de atendimento necessários, é fundamental que as políticas de acolhimento também sejam contempladas pelas diferentes esferas do poder público para assegurar os direitos de cidadania e promover o bem-estar da população migrante. Portanto, advogamos por políticas de acolhimento tecidas no atravessamento dos eixos vertical, representado pelas instituições do Estado e pelas empresas, e horizontal, representado pelas pessoas em suas agências cotidianas.

Assim, acreditamos que acolhimento seja, antes de uma ação, uma perspectiva construída entre os agenciamentos verticais e horizontais, pois

o horizontal e o vertical não se apresentam em uma relação dicotômica, como se fossem duas partes homogêneas de uma simetria. Ambos os eixos estão imbricados em relações de poder que produzem diversas escalas e diferentes 
REVISTA X, Curitiba, volume 13, n.1, p. 57-86, 2018.

\title{
Dossiê Especial: Português como Língua Adicional em contextos de minorias: (co)construindo sentidos a partir das margens BIZON \& DINIZ (Orgs.)
}

\begin{abstract}
tipos de relação entre agentes, espaço e produção. Todo espaço - sempre performativo (BUTLER, 2010/1990) e, portanto, (re)construído discursiva e politicamente nas relações sociais - é perpassado por esses eixos e, embora as verticalidades pareçam mais determinantes na organização das políticas públicas, as horizontalidades criam formas de convivência e de regulação a partir do próprio espaço, por meio de microagências, que podem mudar a realidade. É no atravessamento dessas agências que podemos resistir aos processos de reterritorialização precária (HAESBAERT, 2004), criando possibilidades de apropriação (LEFEBVRE, 1974) dos espaços, ou seja, possibilidades de pertencimento. É também nesse atravessamento que políticas de línguas (MAHER, 2010, 2013; RAJAGOPALAN, 2013), compreendidas aqui não apenas como ações planejadas e executadas de cima para baixo (pelos agentes verticais), mas também de baixo para cima (a partir dos agentes horizontais) podem ser pensadas e efetivadas, alçando ao protagonismo agentes não hegemônicos (BIZON \& CAMARGO, 2018, p. 714).
\end{abstract}

Planejar e gerenciar políticas públicas no atravessamento das verticalidades e das horizontalidades, portanto, significa oficializar as ações que garantam atendimento digno e necessário aos migrantes de crise, colocando-as como um dever do Estado, sem, contudo, ignorar as microagências da sociedade civil. Significa também desassociar acolhimento de caridade e considerar que os migrantes de crise são agentes capazes de transformação social.

Frente ao que foi discutido até aqui, notam-se alguns avanços para as políticas de acolhimento sendo construídos no atravessamento das verticalidades com as horizontalidades. Contudo, para discutir a eficácia desses avanços, é fundamental ouvir a voz daqueles para quem as políticas são direcionadas.

\section{CONSIDERAÇÕES METODOLÓGICAS}

O fenômeno social total representado pelos migrantes, que, como já afirmamos, são emigrantes e imigrantes ao mesmo tempo (SAYAD, 2000), nos leva a considerar tanto a origem como o destino nas discussões acerca da migração internacional. Nesse sentido, Glick-Schiller (1999) propõe o paradigma da "migração transnacional" ou "transmigração". Conforme a autora, trata-se de um padrão de migração em que as pessoas continuam mantendo conexões sociais dentro de seus países de origem ao mesmo tempo em que estabelecem conexões sociais e se assentam no país de destino. Ao viverem por entre as fronteiras, os transmigrantes estabelecem campos sociais 
REVISTA X, Curitiba, volume 13,n.1,p. 57-86, 2018.

Dossiê Especial: Português como Língua Adicional em contextos de minorias:

(co)construindo sentidos a partir das margens

BIZON \& DINIZ (Orgs.)

transnacionais por meio de suas relações familiares, econômicas, políticas, religiosas e sociais.

O paradigma da transmigração permite pensar os migrantes como agentes sociais em mais de um Estado e, assim, rompe com as ideologias do "nacionalismo metodológico" (WIMMER \& GLICK-SCHILLER, 2002 apud BAENINGER \& PERES, 2017, p. 121), perspectiva que só considera o Estado-nação e a formação dos espaços nacionais que gerou categorias como o estrangeiro/estranho, aquele que ameaça a nação provedora de direitos e que, portanto, precisa ser assimilado para pertencer a um determinado Estado-nação (BAENINGER \& PERES, 2017).

A partir do paradigma da transmigração e do entendimento do migrante como fenômeno social total, subjaz a percepção de que a presença dos migrantes em determinado lugar tem implicações políticas, econômicas e sociais tanto no destino quanto na origem. Deriva dessa concepção a imprescindibilidade de considerarmos as duas pontas do projeto migratório (PEREIRA, 2012) - a origem e o destino - a fim de obter uma compreensão mais abrangente das dimensões da migração. Apesar de os participantes da pesquisa apresentada neste artigo serem transmigrantes, já que mantêm vínculos sociais, afetivos e econômicos no Brasil e nos países de origem, o trabalho focaliza apenas as implicações das políticas de acolhimento no destino, o município de São Paulo.

A pesquisa, de base qualitativo-interpretativista, baseia-se na análise das narrativas de dois migrantes de crise. Escolhemos as narrativas (THREADGOLD, 2005; BIZON, 2013) por considerá-las um instrumento de geração e análise de registros bastante adequado para fazer ouvir vozes frequentemente silenciadas.

Os participantes de pesquisa são: Yailin, 50 anos, cubana, artista e professora, que chegou ao Brasil em março de 2014 com seu filho para reunir-se ao seu marido, que já estava morando no país. Tanto Yailin quanto seu marido deixaram Cuba por crerem estar sofrendo perseguição política. O outro participante é Louis, 42 anos, haitiano, professor do Ensino Fundamental, que chegou ao Brasil em setembro de 2016 deixando esposa e duas filhas no Haiti em busca de uma melhor remuneração aqui. Com o intuito de preservar o anonimato dos participantes de pesquisa, qualquer informação que 
REVISTA X, Curitiba, volume 13,n.1,p. 57-86, 2018.

Dossiê Especial: Português como Língua Adicional em contextos de minorias:

(co)construindo sentidos a partir das margens

BIZON \& DINIZ (Orgs.)

pudesse identificá-los, como seus nomes, bairro onde vivem e nome dos locais de trabalho, foram alterados ou omitidos.

As duas narrativas analisadas foram geradas por meio de uma conversa informal áudio-gravada ${ }^{8}$ que objetivou relatar a experiência vivida pelos migrantes em relação à acolhida e às possibilidades de inserção social no país. Após a gravação, as conversas foram transcritas. Também houve trocas de mensagens pelo Messenger na Internet. A partir dos dois objetivos propostos neste trabalho, foram geradas duas seções de análise: uma sobre regulamentação de entrada e permanência e outra sobre as políticas de acolhimento disponíveis.

\section{PARA VIR PARA CÁ, VOCÊ PRECISA COMPRAR VISTO}

Esta seção objetiva analisar, a partir das narrativas dos dois participantes de pesquisa, como os mecanismos de regulamentação de entrada e permanência no país e as políticas de acolhimento disponíveis são vivenciados por esses migrantes. Os excertos de Yailin e de Louis mostram que a legislação regulamentadora da imigração no Brasil bem como as relações intergovernamentais desempenham um papel significativo na elaboração dos projetos migratórios dos participantes.

No caso de Louis, à ocasião de sua chegada em 2016, a Resolução Normativa no 97/2012, que concede os vistos em caráter humanitário aos haitianos, já estava em vigor, permitindo-lhe entrar no Brasil em condições de obter a documentação necessária para residir e trabalhar no país. Por outro lado, a concessão do visto aumentou o custo inicial do projeto migratório, conforme explicitado no seguinte excerto:

Louis: (...) eu tinha muita dificuldade para vir para cá aqui porque eu preciso comprar visto (...) para vir para cá, você precisa comprar visto a duzentos sessenta dólar americano, depois você precisa comprar passagem muito cara, depende do mês, se tem férias, se não tem férias. Eu comprei passagem pra mil quinhentos dólar americano para vir aqui.

\footnotetext{
${ }^{8}$ Esses dados são parte de um corpus maior gerado para minha pesquisa de doutorado em andamento, com financiamento da CAPES, cujo objetivo é levantar algumas implicações para um protocolo que objetive a (re)formulação de políticas (vigente e/ou futuras) de acolhimento e de línguas.
} 
REVISTA X, Curitiba, volume 13,n.1,p. 57-86, 2018.

Dossiê Especial: Português como Língua Adicional em contextos de minorias:

(co)construindo sentidos a partir das margens

BIZON \& DINIZ (Orgs.)

De acordo com Baeninger \& Peres (2017, p. 124), a criação de um visto humanitário em caráter excepcional para os migrantes haitianos em vez da concessão do status de refugiado, está pautada no "mito do terremoto". A legislação brasileira interpreta que as solicitações de refúgio feitas por haitianos provêm das situações adversas intensificadas pelo terremoto de 12 de janeiro de 2010 e, portanto, não se enquadram nos critérios para a classificação de refugiado definidos em lei e convenções internacionais ${ }^{9}$. No entanto, a medida pode indicar a intenção do Governo brasileiro de diminuir o fluxo migratório haitiano para o país, uma vez que passou a obrigar a "compra" de um visto para ingressar no país, encarecendo o projeto migratório para os haitianos. Em outras palavras, a ajuda humanitária representada na concessão de um visto específico tem um preço a ser pago. A dificuldade para vir para cá relatada por Louis pode ser estendida para além do alto custo financeiro. Fernandes \& Faria (2016, p. 102) destacam que, além dos US\$200,00 para a emissão do visto, “o postulante deve ter passaporte em dia, ser residente no Haiti (o que deve ser comprovado por atestado de residência) e apresentar atestado de bons antecedentes". Portanto, para muitos haitianos, a obtenção do visto humanitário apresenta-se como um processo difícil.

A escolha lexical de Louis pelo verbo "comprar" em sua narrativa ajuda a enfatizar sua compreensão a respeito da dificuldade enfrentada pelos haitianos na obtenção de vistos, que, para ele, se traduz em um processo pautado em uma relação muito mais comercial de compra e venda de vistos do que em uma ação humanitária de concessão de vistos. Nesse sentido, uma política vertical - a concessão de visto humanitário, que, em um primeiro momento, pareceu estar preocupada em combater a forma precária da imigração haitiana para o Brasil - acabou se revelando um mecanismo de seleção de migrantes com base em critérios de proteção nacional e condição financeira, em vez de Direitos Humanos.

\footnotetext{
${ }^{9}$ Os critérios para a concessão do status de refugiado expressos na Lei $n^{\circ}$ 9.474/1997, que incorpora a Convenção de 1951, o Protocolo de 1967 e a Declaração de Cartagena de 1984, resumem-se em perseguição política, guerras ou perseguição e conflitos de qualquer natureza. No entanto, o reconhecimento da necessidade ou não da proteção do Estado brasileiro é subjetivo, ficando a cargo de um entrevistador do CONARE - Comitê Nacional para Refugiados ou servidor público da Defensoria Pública da União (LEÃO, 2017, p. 2015).
} 
REVISTA X, Curitiba, volume 13,n.1,p. 57-86, 2018.

Dossiê Especial: Português como Língua Adicional em contextos de minorias:

(co)construindo sentidos a partir das margens

BIZON \& DINIZ (Orgs.)

Yailin recorreu ao pedido de visto de estudante como estratégia para ingressar e permanecer no Brasil. Apesar de se considerar refugiada, uma vez que se sentiu compelida a deixar Cuba por julgar que se encontrava em uma situação de perseguição política devido a sua atuação crítica na formação de professores, Yailin relatou que decidiu não solicitar refúgio por supor como subjetivo o embasamento de sua constatação, algo que levaria ao indeferimento do pedido. A suposição de indeferimento de seu pedido de refúgio reflete as estatísticas levantadas pelo Comitê Nacional para os Refugiados, segundo as quais houve 1.370 solicitações de refúgio feitas por cubanos em 2016 e nenhum deferimento (BRASIL, 2017).

A escolha relatada de Yailin mostra que, a despeito de termos uma lei de refúgio avançada e humanista - a Lei 9.474/97 -, é possível que a decisão favorável ou não dos agentes encarregados de analisar as solicitações de refúgio seja influenciada pelas relações político-diplomáticas entre os governos, já que não se conhecem os mecanismos de filtro dos pedidos que recebem o deferimento ou não. Conforme nos esclarece Leão (2017, p. 220) sobre a entrevista realizada como parte do processo de requerimento de refúgio no Brasil, em sua "busca pela verdade real dos fatos [...], o entrevistador poderá coletar dados e informações do país de origem, traçar um perfil e um roteiro de perguntas que o auxiliará na função”. O entrevistador, portanto, atua como um juiz dos fatos narrados pelo solicitante de refúgio. Dessa forma, entrevistador e solicitante compartilham o ônus da prova, uma vez que "não somente o solicitante deverá provar seu fundado temor de perseguição assim como é dever do entrevistador auferir daquelas declarações a necessidade ou não da proteção internacional" (ibidem, p. 220-221). Na interpretação de Yailin, uma guerra no país de origem reconhecida internacionalmente poderia justificar sua condição de refugiada para as autoridades brasileiras e, talvez, tê-la encorajado a solicitar refúgio, mas esse não é seu caso:

Yailin: Eu cheguei de uma forma meio atípica aqui ao Brasil comparando-me com outros refugiados que vêm da guerra, tudo isso... eu consegui entrar na universidade ${ }^{10}$, Instituto de Artes...

\footnotetext{
${ }^{10} \mathrm{O}$ nome da universidade foi omitido para preservar o anonimato da participante.
} 
REVISTA X, Curitiba, volume 13,n.1,p. 57-86, 2018.

Dossiê Especial: Português como Língua Adicional em contextos de minorias:

(co)construindo sentidos a partir das margens

BIZON \& DINIZ (Orgs.)

Diferentemente do visto humanitário, que assegura o direito à obtenção da Carteira de Trabalho e Previdência Social e, portanto, possibilita o emprego formal a Louis, o visto de estudante de Yailin não lhe permite manter vínculo empregatício no país, diminuindo suas oportunidades de emprego em sua área de formação ou de interesse, e, consequentemente, a própria possibilidade de se sentir parte constituinte da sociedade. Ao negar a possibilidade de obter vínculo empregatício aos migrantes, a legislação vigente pode ser vista como um instrumento que restringe a inserção social, gerando, muitas vezes, (re)territorializações precárias (HAESBAERT, 2004; BIZON, 2013), conforme aponta o seguinte diálogo:

Yailin: $\quad$ A gente não tem tudo para conseguir o emprego que mais gostasse, que mais aponte com sua natureza de estudos e de interesses, mas é graças que eu tenho esse emprego aqui [...] primeiro, as leis brasileiras não são abertas para todo mundo, quando você vai buscar trabalho, tem que ter carteirinha. Você, se é estrangeiro, não tem carteirinha. Bom, eu não tenho a carteirinha e nem posso ter, por isso, estou trocando de visto, para poder ter essa condição.

Helena: Qual carteirinha?

Yailin: De trabalho, CLT. [...] Cada edital que abre de sua área para poder trabalhar, a maioria fala tem que ser brasileiro. Tem alguns que falam que não precisa ser brasileiro, que pode ser residente de outro país (...), mas, quando a gente propõe, leva currículo, tudo isso (...), eles falam não, não pode ser estrangeiro e você não consegue mais fazer o que gostaria de fazer.

Além da frustração de não conseguir fazer o que se gostaria, o enunciado de Yailin mostra que a proteção ao território nacional na legislação é estendida aos nacionais, tornando a nacionalidade nacional um fator de exclusão dos migrantes de crise na competição por emprego. A nova lei 13.445/2017 de migração, em seu artigo 14 , no parágrafo $5^{\circ}$, prevê a concessão de visto temporário de trabalho ao migrante que

venha exercer atividade laboral, com ou sem vínculo empregatício no Brasil, desde que comprove oferta de trabalho formalizada por pessoa jurídica em atividade no País, dispensada esta exigência se o imigrante comprovar titulação em curso de ensino superior ou equivalente (BRASIL, 2017).

No entanto, para que essa lei possa ser efetivamente considerada um avanço, é importante que suas diretrizes não sejam regulamentadas a partir da mesma perspectiva seletiva que prioriza o migrante qualificado, reforçando as diferenças entre desejáveis e indesejáveis do passado, criando, assim, mais formas de racialização e menos formas de 
REVISTA X, Curitiba, volume 13,n.1,p.57-86, 2018.

Dossiê Especial: Português como Língua Adicional em contextos de minorias:

(co)construindo sentidos a partir das margens

BIZON \& DINIZ (Orgs.)

(re)territorialização efetiva. Embora seja crucial viabilizar o trabalho legal no país e valorizar a formação profissional e acadêmica dos migrantes de crise, não se deve esquecer que esses migrantes precisam ser vistos sempre sob a perspectiva dos Direitos Humanos, e não meramente como peças úteis ao desenvolvimento da nação, igualando migrante à força de trabalho como no passado (SEYFERTH, 2008).

Portanto, além de leis favoráveis à agência dos migrantes de crise, são necessárias políticas públicas para balizar ações direcionadas a seu acolhimento, principalmente, no momento de chegada.

\section{NÃO, NÃO FALA NADA DE ESPANHOL, TUDO EM PORTUGUÊS}

Nesta seção, analisa-se como os participantes da pesquisa vivenciaram as políticas de acolhimento disponíveis no momento de sua chegada ao país.

Observa-se, na tessitura dos dizeres de Louis e de Yailin, que as ações que mais fazem falta no momento de chegada, em que é necessário obter documentação para se regularizar no país e ter acesso aos direitos sociais, são aquelas que envolvem a língua:

Louis: Quando eu cheguei aqui, eu tinha muita dificuldade porque eu falei francês, crioulo haitiano só, sabia nada em português, sabia nada. $\mathrm{Na}$ verdade, sabia nada, só bom dia, boa tarde, como vai, só. Eu morei com um amigo e estava muito difícil para mim porque ele trabalhou à noite, ele não podia me ajudar quando eu precisava fazer documentos. Eu passei um mês em casa, só ficar em casa.

Yailin: $\quad$ Não, não fala nada de espanhol, tudo em português, os papéis que eu tive que fazer aqui na Polícia Federal tudo em português, e se eu não entendia nada, bom, eu tive que voltar, voltar a perguntar e tentar não quebrar a paciência deles, ser muito amável, mas esforçar a amabilidade para que eles não fechem e eles consigam lidar com uma pessoa que não fala seu idioma.

Nenhum dos dois migrantes deixou de obter sua documentação, mas suas narrativas indicam que esse foi um processo mais longo e mais estressante do que deveria ou poderia ter sido, caso houvesse políticas linguísticas que assegurassem o ensino e a exigência de línguas adicionais aos servidores bem como tradutores e intérpretes nos serviços públicos. As narrativas de Louis e de Yailin endossam os resultados de uma pesquisa realizada pelo IPEA sobre os obstáculos de acesso a 
REVISTA X, Curitiba, volume 13,n.1,p. 57-86, 2018.

Dossiê Especial: Português como Língua Adicional em contextos de minorias:

(co)construindo sentidos a partir das margens

BIZON \& DINIZ (Orgs.)

atendimento e serviços enfrentados pelos migrantes de crise que apontaram o idioma como a principal dificuldade (OLIVEIRA \& SILVA, 2017).

O excerto de Louis indica que a rede migratória, representada por seu amigo, desempenha um papel importante nos encaminhamentos para a obtenção de documentação. Ainda assim, nem sempre essa ajuda está disponível quando ela é mais necessária, resultando em uma demora ainda maior para procurar emprego e sociabilizar. Embora o CRAI-SP já estivesse funcionando quando Louis chegou ao Brasil, ele não sinaliza ter conhecimento desse centro, criado especificamente para dar orientação aos imigrantes.

Yailin sugere a indisponibilidade de atendentes da Polícia Federal em entender suas dúvidas e também em se esforçar para se comunicar com ela, esperando que o migrante despenda esforços para se comunicar e interagir em um movimento de mão única. A impressão de Yailin sobre a atitude dos atendentes parece se aproximar de uma perspectiva assimilacionista, pois há a expectativa de que o Outro se adeque, evitando que suas diferenças incomodem os locais. Essa atitude vai contra as diretrizes da Lei Municipal de Migração 16.478/2016, que prevê a formação dos agentes públicos para a interculturalidade e a aprendizagem de línguas além de da contratação de servidores migrantes, sinalizando a necessidade de estender essas premissas para o âmbito federal também.

É relevante destacar que toda interação entre aqueles que não são proficientes na língua majoritária do país, como migrantes de crise e indígenas, por exemplo, e um juiz, um policial ou um médico é estabelecida em uma relação de subordinação dos primeiros aos últimos (VARENNES, 2014 apud OLIVEIRA \& SILVA, 2017). Na memória de Yailin, ela aparece protagonizando um evento em que teria precisado agir amavelmente, a despeito de sua ansiedade, sugerindo, assim, sua subjugação em relação aos agentes da Polícia Federal.

Quanto ao ensino da língua portuguesa, a narrativa de Louis confirma a afirmação de Amado (2013) de que é a sociedade civil, representada pelas organizações não governamentais e instituições religiosas, que têm desenvolvido esse trabalho com o apoio do voluntariado: 
REVISTA X, Curitiba, volume 13,n.1,p. 57-86, 2018.

\section{Dossiê Especial: Português como Língua Adicional em contextos de minorias: (co)construindo sentidos a partir das margens BIZON \& DINIZ (Orgs.)}

Louis: Eu tenho um amigo, ele falou pra mim "tem uma escola aqui na Missão Paz"11", eu não sabia, ele falou pra mim "tem uma escola aqui na Missão Paz, por que você não vai? Um dia, eu cheguei aqui, eu cheguei aqui, eu fiz inscrição, depois eu comecei a pegar aula de português aqui.

Endossando o apelo de Amado (2013) e de Lopez \& Diniz (no prelo) no que diz respeito ao papel das Instituições Superiores de Ensino, ressalto a urgência de ações nos campos da pesquisa, do ensino e da extensão voltadas aos migrantes de crise, principalmente no que se refere ao ensino da língua portuguesa a essa população. É incompreensível que, tendo um compromisso com a construção de um mundo mais igualitário, uma universidade pública não possa ofertar um curso de Português como Língua Adicional aos migrantes de crise sem cobrar por isso, conforme relatado por Yailin:

Helena: Você chegou a fazer aula de português aqui? Foi oferecido algum curso?

Yailin: Não. Eu perguntei desde que cheguei à universidade, por favor, tem aulas de português para estudantes da pós-graduação? Não tem.

Helena: Nem na universidade e nem em outro lugar?

Yailin: Não. E onde tem aulas de português, boas, é na USP, mas eu não era estudante na USP.

Helena: Então, você não tinha direito?

Yailin: Eu tinha direito se eu pagava a mesma conta que qualquer um da rua que não é estudante da USP, eu não consigo pagar mais de seiscentos reais [pausa] nem menos, ou seja, o curso vale, não sei, seiscentos, oitocentos reais, como que vou pagar isso para estudar português?

Considerando a aprendizagem da língua oficial um direito dos migrantes (OLIVEIRA \& SILVA), ela não deve lhes acarretar custos financeiros. É nesse sentido que concordo com Lopez (2016; 2018, neste dossiê) a respeito da utilização de um termo específico, como PLAc, para designar o ensino de português para migrantes de crise como um ato político, uma vez que ajuda a visibilizar essa população e suas necessidades. Apesar de as discussões sobre PLAc ainda serem incipientes no Brasil,

\footnotetext{
${ }^{11}$ A Missão Paz é um centro integrado de apoio ao migrante formado pelo Centro Pastoral e de Mediação dos Migrantes, a Casa do Migrante, o Centro de Estudos da Migração (CEM) e as paróquias Nossa Senhora da Paz, Paróquia Pessoal dos Latinos Americanos e Paróquia Pessoal dos Italianos. Localizada no centro de São Paulo, a Missão Paz acolhe, orienta e auxilia todos os tipos de migrantes por meio dos eixos Capacitação e Cidadania, Trabalho, Documentação e Jurídico, Saúde e Comunidade. Essa estruturação da Missão Paz foi modelada, ao longo de sua história, pelas demandas da população migrante, como é exemplo a oferta do curso de português.
} 
REVISTA X, Curitiba, volume 13,n.1,p. 57-86, 2018.

Dossiê Especial: Português como Língua Adicional em contextos de minorias:

(co)construindo sentidos a partir das margens

BIZON \& DINIZ (Orgs.)

elas também parecem seguir na direção de considerar os migrantes de crise sob o olhar dos Direitos Humanos, e isso já é um passo à frente.

\section{CONSIDERAÇÕES FINAIS}

As discussões levantadas neste artigo mostram que os novos fluxos imigratórios no Brasil têm levado o Governo a revisar sua política migratória e responder, ainda que de forma reativa (PARISE, 2016), a algumas demandas de acolhimento de maneira positiva. Contudo, embora em nível local possamos apontar grandes avanços nas políticas verticais voltadas para os migrantes de crise, como a criação do CRAI-SP e a Lei Municipal de Imigração de São Paulo, as ações desencadeadas a partir dessas políticas ainda não puderam ser sentidas pelos participantes desta pesquisa, apontando para duas possíveis conclusões: (i) as ações ainda são muito incipientes e (ii) outras ações se fazem necessárias para que os migrantes tenham conhecimento delas.

As análises dos excertos de Louis e de Yailin indicam a necessidade de substituição da Lei $n^{\circ}$ 6.815/80, vigente até novembro de 2017, por uma legislação mais adequada às novas realidades migratórias. A nova lei, que tem em seu cerne o objetivo de proteger e promover os direitos dos migrantes, amplia as possibilidades de entrada e permanência no país por meio do visto humanitário. No entanto, vale apontar que, apesar de a regulamentação desse dispositivo ser crucial para manter o verdadeiro objetivo da lei, ela foi protelada para uma regulação posterior ${ }^{12}$.

No que tange a promoção da agência dos migrantes de crise, a barreira linguística é indicada como um grande entrave. O suprimento das demandas linguísticas, como o ensino/aprendizado da língua portuguesa e traduções, está a cargo de iniciativas da sociedade civil organizadas em políticas horizontais. Ressaltamos a urgência, já apontada por Oliveira e Silva (2017), de políticas de línguas que ofertem intérpretes e tradutores em órgãos públicos, principalmente naqueles encarregados de emitir os documentos necessários para a regularização dos migrantes no país e seu

\footnotetext{
12 Disponível em < https://www.cartacapital.com.br/politica/regulamento-da-lei-da-migracao-e-umacatastrofe-diz-especialista>. Acesso: 19/01/2018.
} 
REVISTA X, Curitiba, volume 13,n.1,p. 57-86, 2018.

\section{Dossiê Especial: Português como Língua Adicional em contextos de minorias:}

(co)construindo sentidos a partir das margens

BIZON \& DINIZ (Orgs.)

consequente acesso aos direitos sociais. Não é só no âmbito das línguas que as políticas públicas deverão sofrer mudanças estruturais; as políticas de saúde e de assistência social e previdência para migrantes também deverão ser revistas conforme o cenário populacional do país atinja as expectativas de envelhecimento demográfico, descritas por C. Anunciação $(2018)^{13}$, e um aporte de imigrantes passe a ser necessário para recompor a força de trabalho e manutenção do crescimento econômico. O autor aponta, ainda, a inevitabilidade de se incluir a Lei 13.444/17 como matéria de estudo e avaliação nos concursos públicos para ingresso nas carreiras de Promotor de Justiça e de servidores.

A partir das reflexões de Maher (2007) quanto à necessidade de ações que tenham em seus princípios a promoção da interculturalidade para o fortalecimento político dos "grupos minoritarizados" (LOPEZ, 2018, neste dossiê), como é o caso dos migrantes de crise, considero que as políticas de línguas voltadas para a população migrante devam ir além do PLAc, abarcando também a promoção do ensino de línguas adicionais aos brasileiros e a oferta de tradutores e intérpretes nos órgãos públicos.

A promoção e efetivação de leis favoráveis aos migrantes, somadas ao rompimento das barreiras linguísticas, pavimentam o envolvimento social, político e econômico com o novo território, ou seja, sua (re)territorialização. De pouco adianta passarmos a possibilitar a concessão de vistos humanitários a altos cultos financeiros, criarmos centros de acolhimento a migrantes que não chegam ao conhecimento dos interessados ou disponibilizarmos as informações necessárias para obtenção de documentos e para acesso aos direitos sociais em várias línguas em um link escrito somente em português no site da prefeitura de um município, por exemplo. Para abrirmos, de fato, as portas do país aos migrantes de crise, as políticas públicas voltadas a eles precisam considerar, em seu bojo, como elas se farão conhecer por eles e como serão efetivadas, sem o que as portas do Brasil continuarão apenas entreabertas.

\section{REFERÊNCIAS}

AMADO, R. S. O ensino de português como língua de acolhimento para refugiados. Revista da Sociedade Internacional Português Língua Estrangeira, v. 4, n. 2, 2013.

\footnotetext{
${ }^{13}$ Para detalhes das estatísticas discutidas pelo autor, ver C. Anunciação (2018).
} 
REVISTA X, Curitiba, volume 13,n.1,p. 57-86, 2018.

Dossiê Especial: Português como Língua Adicional em contextos de minorias:

(co)construindo sentidos a partir das margens

BIZON \& DINIZ (Orgs.)

Disponível em: <http://www.siple.org.br/index.php?option= com_content\&view= article \&id=309:o-ensino-de-portugues-comolingua-de-acolhimento-pararefugiados\&catid=7 0:edicao-7\&Itemid=113 >. Acesso em 10 set. 2017.

ANUNCIAÇÃO, R. F. M. Somos mais que isso: Práticas de (re)existência de migrantes e refugiados frente à despossessão e ao não reconhecimento. Dissertação (Mestrado em Linguística Aplicada). Instituto de Estudos da Linguagem (IEL), Universidade Estadual de Campinas, 2017.

A língua que acolhe pode silenciar? Reflexões sobre o conceito de "Português como Língua de Acolhimento". Curitiba, Revista X, v.13, n.1, p.57-56, 2018.

ANUNCIAÇÃO, C. S. A necessidade de reestruturar as agendas dos ministérios públicos estaduais para dar efetividade à Nova Lei de Migração. In: BAENINGER et al (Orgs.). Migrações Sul-Sul. Campinas,SP: NEPO/UNICAMP, 2018. p. 624-636.

APPADURAI, A. O medo ao pequeno número. Tradução: Ana Goldberger. São Paulo: Editora Iluminuras, 2006/2009.

BAENINGER, R. et al. (Orgs.). Migrações Sul-Sul. Campinas: NEPO/UNICAMP, 2018.

BAENINGER, R. A.; PERES, R. G. Migração de crise: a imigração haitiana para o Brasil. Revista Brasileira de Estudos da População. Belo Horizonte, v. 34, n. 1, p. 119-143, jan./abr. 2017. Disponível em: $<$ http://www.scielo.br/s cielo.php ?script $=$ sci _arttext \&p i d=S010230982017000100119\&lng=pt\&nrm=iso. $>$ Acesso em: $12 / 09 / 2017$.

BIZON, A. C. C. Narrando o exame Celpe-Bras e o convênio PEC-G: a construção de territorialidades em tempos de internacionalização. Tese. Doutorado em Linguística Aplicada. Campinas: Universidade Estadual de Campinas, 2013.

BIZON, A. C. C.; CAMARGO, H. R. E. Acolhimento e ensino da língua portuguesa à população oriunda de migração de crise no município de São Paulo: Por uma política do atravessamento entre verticalidades e horizontalidades. In: BAENINGER et al (Orgs.). Migrações Sul-Sul. Campinas: NEPO/UNICAMP, 2018. p. 712-726.

BIZON, A. C. C.; CAVALCANTI, M. C. Narrating lived experiences from the margins: the voices of two undergraduate students from the Democratic Republic of Congo at a Brazilian university. In: CAVALCANTI, M. C.; MAHER, T.J.M. (Orgs.). Multilingual Brazil: language resources, identities and ideologies in a globalized world. New York: Routledge, 2018. p. 225-240.

BRASIL. Congresso Nacional. Lei no 6.815 de 19 de agosto de 1980. Define a situação jurídica do estrangeiro no Brasil, cria o Conselho Nacional de Imigração. 
REVISTA X, Curitiba, volume 13,n.1,p. 57-86, 2018.

Dossiê Especial: Português como Língua Adicional em contextos de minorias:

(co)construindo sentidos a partir das margens

BIZON \& DINIZ (Orgs.)

Diário Oficial [da] República Federativa do Brasil, Poder Executivo, Brasília, DF, 21 ago. $1980 . \quad$ p. $16533 . \quad$ Disponível em: <http://www.planalto.gov.br/ccivil_03/Leis/L6815>.htm. Acesso em 10/09/2017.

Congresso Nacional. Lei no 9.474, de 22 de julho de 1997. Define mecanismos para a implementação do Estatuto dos Refugiados de 1951, e determina outras providências. Diário Oficial [da] República Federativa do Brasil, Poder Executivo, Brasília, DF, 23 jul. 1997, p. 15822. Disponível em: $<$ http://pesquisa.in.gov.br/imprensa/jsp/visualiza/index.jsp?jornal=1\&pagina=22\&data= 23/07/1997>. Acesso em 10/09/2017.

Lei no 13.445, de 24 de maio de 2017. Institui a Lei de Migração. Disponível em: <http://www.planalto.gov.br/ccivil_03/_ato2015-2018/2017/lei/L13445.htm. Acesso em 10/09/2017>. Acesso em 10/09/2017.

Refúgio em números - Ministério da Justiça e Segurança Pública. Disponível em <http://www.justica.gov.br/news/brasil-tem-aumento-de-12-no-numero-de-refugiadosem-20 16/20062017_refugio-em-numeros-2010-2016.pdf/view>. Acesso em: 04/03/2018.

BUTLER, J.. Problemas de gênero. Rio de Janeiro: Civilização Brasileira, 2010/1990. . Undoing gender. Nova Iorque/Londres: Routledge. 2004

CABETE, M.A. O processo de ensino-aprendizagem do português enquanto língua de acolhimento. Dissertação (Mestrado em Língua e Cultura Portuguesa) Universidade de Lisboa, Lisboa, 2010.

CAMPOS, C. M. A política da língua na era Vargas. Campinas: Editora da UNICAMP, 2006.

CAVALCANTI, M. C. Estudos sobre educação bilíngue e escolarização em contextos de minorias linguísticas no Brasil. D.E.L.T.A., vol.15, n. especial, p. 385-417, 1999.

FERNANDES, D.; FARIA, A. V. A diáspora haitiana no Brasil: processo de entrada, características e perfil. In: BAENINGER et ali (orgs.). Imigração haitiana no Brasil. Jundiaí: Paco Editorial, 2016. P. 94-111.

GLICK-SCHILLER, N. Transmigrants and Nation-States: something old and something new in the US immigrant experience. In: HIRSCHMAN, C. et al. (eds.) Handbook of international migration: the American experience.. Nova Iorque: Russel Sage, 1999. P. 94-118.

GONÇALVES, A. J. A mobilidade humana e a globalização: fenomenologia e desafios. Instituto Migrações e Direitos Humanos, Brasília, 2005. Disponível em $<\mathrm{http}$ ://www.migrante.org.br/migrante/index.php?option=com_content\&view=article\&i 
REVISTA X, Curitiba, volume 13,n.1,p. 57-86, 2018.

Dossiê Especial: Português como Língua Adicional em contextos de minorias:

(co)construindo sentidos a partir das margens

BIZON \& DINIZ (Orgs.)

d=169:a-mobilidade-humana-e-a-globalizacao-fenomenologia-e-desafios \&catid $=88 \&$

Ite mid=1211>. Acesso em 20/09/2017.

GROSSO, M.J. Língua de acolhimento, língua de integração. Revista Horizontes de Linguística Aplicada, v. 9, n. 2, p. 61-77, 2010.

HAESBAERT, R. O Mito da desterritorialização. Do "fim dos territórios" à multiterritorialidade. Rio de Janeiro: Editora Bertrand Brasil, 2004.

LEÃO, F. R. R. Do procedimento de determinação da condição de refugiado: da solicitação até a decisão pelo Comitê Nacional para Refugiados. In: JUBILUT; GODOY (Orgs.). Refúgio no Brasil: comentários à Lei 9.474/97. São Paulo: Quartier Latin/ACNUR, 2017. p. 215-226.

LEFEBVRE, H. La production de l'espace. Paris: Anthropos, 1986/1974.

LOPEZ, A. P. A. Subsídios para o planejamento de cursos de português como língua de acolhimento para imigrantes deslocados forçados no Brasil. 2016. $260 \mathrm{f}$. Dissertação (mestrado em Linguística Aplicada) - Universidade Federal de Minas Gerais, Belo Horizonte, 2016.

LOPEZ, A. P. A. A aprendizagem de português por imigrantes deslocados forçados no Brasil: uma obrigação? Curitiba, Revista X, v.13, n.1, p.9-34, 2018.

LOPEZ, A. P. A.; DINIZ, L. R. A. Iniciativas jurídicas e acadêmicas para o acolhimento no Brasil de deslocados forçados. Revista da Sociedade Internacional Português Língua Estrangeira. Revista da Siple, no prelo.

MAGALHÃES, J. L. Q. Plurinacionalidade e cosmopolitismo: a diversidade cultural das cidades e diversidade comportamental nas metrópoles. Revista da Faculdade de Direito UFMG, Belo Horizonte, n. 53, p. 201-216, jul. - dez. 2008.

MAHER, T. M. A educação do entorno para a interculturalidade e o plurilinguismo. In: KLEIMAN, A. e CAVAlCANTI, M. C. (Orgs.) Linguística Aplicada - suas faces e interfaces. Campinas, SP: Mercado das Letras, 2007, p. 255-270.

. Ecos de resistência: políticas linguísticas e línguas minoritárias no Brasil. In: NICOLAIDES et al. (Orgs.). Política e políticas linguísticas. Campinas, SP: Pontes Editores, 2013, p. 117-133.

MAKONI S.; PENNYCOOK, A. Disinventing and (re) constituting languages. Critical Inquiry in Language Studies: an international journal, v. 2, n. 3, p. 137-156, 2005.

OLIVEIRA, G. M.; SILVA, J. I. Quando barreiras linguísticas geram violação de direitos humanos: que políticas linguísticas o Estado brasileiro tem adotado para 
REVISTA X, Curitiba, volume 13,n.1,p. 57-86, 2018.

Dossiê Especial: Português como Língua Adicional em contextos de minorias:

(co)construindo sentidos a partir das margens

BIZON \& DINIZ (Orgs.)

garantir o acesso dos imigrantes a serviços públicos básicos? Gragoatá, Niterói, v. 22, n. 42, p. 131-153, jan-abr. 2017.

OOMEN, B. Beyond the Nation State? Glocal citizenship and its consequences for integration. In: BAUBÖCK, R.; TRIPKOVIC, M. (Eds.) The integration of migrants and refugees: An EUI forum on migration, citizenship and demography. Florence: European University Institute, 2017. p. 57 - 60.

PARISE, P. A Missão Paz e a acolhida a imigrantes haitianos e haitianas em São Paulo. In: BAENINGER et al. (Orgs.). Imigração haitiana no Brasil. Jundiaí: Paco Editorial, 2016. p. 409-425.

PEREIRA, J. C. A. O lugar desmanchado, o lugar recriado? Enredos e desenredos de jovens rurais na migração internacional. 2012. Tese (Doutorado em Sociologia) Instituto de Filosofia e Ciências Humanas da Universidade Estadual de Campinas, Campinas.

RAJAGOPALAN, K. Política linguística: do que se trata, afinal? In: NICOLAIDES et al. (Orgs.). Política e políticas linguísticas. Campinas, SP: Pontes Editores, 2013, p. $19-42$.

SANTOS, M. Por uma outra globalização: do pensamento único à consciência universal. Rio de Janeiro/São Paulo: Editora Record, 2001.

SÃO BERnARDO, M. A. Português como Língua de Acolhimento: um estudo com imigrantes e pessoas em situação de refúgio no Brasil. 2016. 206 f. Tese (Doutorado em Linguística). Programa de Pós-graduação em Linguística, Universidade Federal de São Carlos, 2016.

SÃO PAULO. Lei no 16.478 , de 08 de julho de 2016. Institui a Política Municipal para a População Imigrante, dispõe sobre seus objetivos, princípios, diretrizes e ações prioritárias, bem como sobre o Conselho Municipal de Imigrantes.

SASSEN, S. Brutality and complexity in the global economy. Cambridge/Massachusetts/Londres: The Belknap press of Harvard University press, 2014.

SAYAD, A. O retorno: elemento constitutivo da condição do migrante. Travessia, São Paulo, v. 13, número especial, p. 7-32, jan. 2000.

SEYFETRH, G. Imigrantes, estrangeiros: a trajetória de uma categoria incomoda no campo político. Trabalho apresentado na 26. Reunião Brasileira de Antropologia, 1-4 jun. 2008. Porto Seguro. Disponível em: <http://www.abant.org.br/conteudo/ANAIS/CD_Virtual_26_RBA/mesas_redondas/trab alhos/MR\%2012/giralda\%20seyferth.pdf>. Acesso em: 21/09/2017. 
REVISTA X, Curitiba, volume 13,n.1,p.57-86, 2018.

Dossiê Especial: Português como Língua Adicional em contextos de minorias:

(co)construindo sentidos a partir das margens

BIZON \& DINIZ (Orgs.)

A dimensão cultural da imigração. Revista Brasileira de Ciências

Sociais. Vol. 26, $\mathrm{n}^{\mathrm{o}}$ 77, p. 47-62, out. 2011.

THREADGOLD, T. Performing theories of narrative: Theorising narrative performance.

In: THORNBORROW, J.; COATES, J. The sociolinguistics of narrative. Amsterdam/Philadelphia: John Benjamins Publishing Company, 2005.

VAINER, C. B. Estado e migração no Brasil: da imigração à emigração. In: PATARRA, N. L. (Coord.). Emigração e imigração internacionais no Brasil Contemporâneo. São Paulo: FNUAP, 1995. p. 39-52.

VARENNES, F. Mediations and Language Rights: a human rights perspective In: DJEFFAL et al. (Orgs.). Mediação e Conlitos Internacionais. São Luís: Procuradoria Geral de Justiça do Estado do Maranhão/Jornal da Justiça/Cultura, Direito e Sociedade (DGP/CNPq/UFMA), 2014. p.73-81. Disponível em: < http://www.iiamainternational.com/editora_livros/8_mediacao_e_conflitos_internaciona is.pdf >. Acesso em 2 dez. 2016.

WENDEN, C. W. As novas migrações: por que mais pessoas do que nunca estão em circulação e para onde elas estão indo? SUR Revista Internacional de Direitos Humanos: São Paulo, v. 13, n. 23, 248 p. jul. 2016.

WIMMER, A.; GLICK-SCHILLER, N. Methodological nationalism and beyond: nation-state building, migration and the social sciences. Global Networks, v. 4, n. 2, p. 303-334, 2002. 